\title{
UMBILICAL VEIN INJECTION OF MISOPROSTOL VERSUS NORMAL SALINE FOR THE TREATMENT OF RETAINED PLACENTA IN A TERTIARY CARE CENTRE- A NON-RANDOMISED CONTROLLED TRIAL
}

\author{
Kajal Kumar Patra', Shibram Chattopadhyay², Amarnath Dey33, Chaitali Sarkar 4 , Anaindita Chakraborty5, Shritanu Bhattacharyya ${ }^{6}$ \\ ${ }^{1}$ Associate Professor, Department of Obstetrics and Gynaecology, Bankura Sammilani Medical College. \\ ${ }^{2}$ Associate Professor, Department of Obstetrics and Gynaecology, Nil Ratan Sircar Medical College. \\ ${ }^{3}$ Postgraduate Trainee, Department of Obstetrics and Gynaecology, BSMC. \\ ${ }^{4}$ RMO-cum-Clinical Tutor, Department of Obstetrics and Gynaecology, College of Medicine and JNM Hospital, Kalyani. \\ 5 Postgraduate Trainee, Department of Community Medicine, North Bengal Medical College. \\ 6Professor, Department of Obstetrics and Gynaecology, NRSMCH, Kolkata.
}

ABSTRACT
BACKGROUND
Many cases of PPH are associated with retained placenta, having great impact on maternal mortality and morbidity worldwide. The
aim of our study was to evaluate the efficacy of intraumbilical misoprostol versus normal saline injection as a treatment for
retained placenta after vaginal delivery to reduce the incidence of manual removal of placenta and blood loss associated with it.

\section{MATERIALS AND METHODS}

It was a hospital-based, non-randomised controlled trial study carried out in the Department of Obstetrics and Gynaecology, Bankura Sammilani Medical College and Hospital, Bankura for one year period from April 2015 to March 2016. The study group of total 50 mothers received $800 \mathrm{mcg}$ of misoprostol dissolved in $25 \mathrm{~mL}$ of normal saline and injected by Pipingas technique through umbilical vein. In control group, a total of 50 mothers received $25 \mathrm{~mL}$ NS injected by Pipingas technique through umbilical vein. Outcome measures were expulsion of the placenta, need for manual removal of the placenta under anaesthesia and amount of blood loss.

\section{RESULTS}

Total number of patients requiring manual removal of placenta in the entire study population $(n=100)$ was 26 . Total $16 \%(n=8)$ patients among misoprostol group $(n=50)$ underwent manual removal, while $36 \%(n=18)$ of patients underwent manual removal of placenta in normal saline group $(n=50)$ which was statistically significant with p value $<0.05$. In terms of duration of third stage of labour (time calculated after 30 mins) and amount of blood loss (mL), median values of both the parameters were less in misoprostol group than normal saline group and the results were statistically significant $(p=0.00)$.

\section{CONCLUSION}

Intraumbilical misoprostol is a promising tool for treatment of retained placenta; it acts by placing misoprostol directly to the placental bed. As per our study, we concluded that intraumbilical misoprostol significantly reduces the need for manual removal of placenta. The success rates were 84\% (42/50) in intraumbilical misoprostol group compared to 64\% (32/50) in saline group. The proportion of patients requiring manual removal of placenta in the intraumbilical misoprostol arm (8/50 patients, 16\%) was lower than that in the intraumbilical saline arm $(18 / 50$ patients, $36 \%)$, (p value $<0.05$ ).

\section{KEYWORDS}

Outcome, Post-Partum Haemorrhage, Intraumbilical Misoprostol, Manual Removal of the Placenta, Retained Placenta, Active Management of Third Stage of Labour.

HOW TO CITE THIS ARTICLE: Patra KK, Chattopadhyay S, Dey A, et al. Umbilical vein injection of misoprostol versus normal saline for the treatment of retained placenta in a tertiary care centre- a non-randomised controlled trial. J. Evolution Med. Dent. Sci. 2017;6(60):4384-4387, DOI: 10.14260/Jemds/2017/948

\section{BACKGROUND}

Post-partum Haemorrhage (PPH) is a significant cause of maternal mortality in the developing world. Many cases of PPH are associated with retained placenta, a condition that affects between 0.6 and $3.3 \%$ of normal deliveries. ${ }^{1,2,3}$

Where there is easy access to hospital care and transfusion, mortality from this condition is very low. In many parts of the developing world, however, the case fatality rate is high.

Financial or Other, Competing Interest: None.

Submission 24-04-2017, Peer Review 15-07-2017,

Acceptance 21-07-2017, Published 27-07-2017.

Corresponding Author:

Dr. Shibram Chattopadhyay,

\#67 B, S.N. Banerji Road, Kolkata- 700014.

E-mail: shibramchatt@gmail.com

DOI: $10.14260 /$ jemds $/ 2017 / 948$

\section{(c) $(1)(3)$}

The retained placenta is defined as placenta remains undelivered even after 30 minutes of delivery of foetus (WHO). It is a significant cause of maternal mortality and morbidity throughout the developing world. It complicates $2 \%$ of all deliveries and has a case mortality rate of nearly $10 \%$ in rural areas.

The only effective treatment option available for a retained placenta is Manual Removal of the Placenta (MROP) under anaesthesia which requires an operation theatre setup, skilled obstetricians and anaesthetists and during this procedure the woman is exposed to the risk of the anaesthesia as well as the infective risk that comes from inserting a hand into the uterus. Both risks are higher in resource-poor countries where the prevalence of infections is high and personnel skilled in obstetrics anaesthesia are in short supply. Previously, in various studies intraumbilical oxytocin given in intraumbilical vein directly places this oxytocic to retroplacental myometrium and helps in its 
contraction, thereby preventing PPH and also helps in early separation of placenta. In our study, we have used Misoprostol solution instead of Oxytocin for the same purpose as Misoprostol is cheap, easily available and can be preserved easily and in room temperature.

\section{MATERIALS AND METHODS}

It was a hospital-based, non-randomised controlled trial study carried out in the Department of Obstetrics and Gynaecology, Bankura Sammilani Medical College and Hospital, Bankura, West Bengal, India, during one year period from April 2015 to March 2016. Informed consent was taken. The study was done on the patients admitted in Labour Ward for delivery. Inclusion criteria were gestational age at least 28 weeks, single live foetus with birth weight of the baby more than $1.5 \mathrm{kgs}$ and patient being haemodynamically stable with systolic blood pressure $<140 \mathrm{mmHg}$ and diastolic blood pressure $<90 \mathrm{mmHg}$. Criteria for retained placenta was taken as "placenta not separated after 30 mins of delivery in spite of active management of 3rd stage of labour."

The incidence of retained placenta is $1 \%-2 \%$. The total number of deliveries in our hospital is 20,000 per year. Among the deliveries, 400 (approximately) cases of retained placenta occur annually, out of which 120 cases were admitted in our unit. So sample size is taken for convenience. Out of 120 patients, 20 patients were excluded by exclusion criteria. The study group of total 50 mothers received 800 mcg of misoprostol dissolved in $25 \mathrm{~mL}$ of normal saline and injected by Pipingas technique through umbilical vein. In control group, total 50 mothers received $25 \mathrm{~mL}$ NS injected by Pipingas technique through umbilical vein. Outcome measures were expulsion of the placenta, need for manual removal of the placenta under anaesthesia and amount of blood loss. Ethical permission from the Institutional Ethics Committee and informed consent from patient and/or relatives were taken prior to the study and interventions.

The whole data was analysed on computer based programme SPSS version 10.0. Descriptive statistics were used to present demographic status of the participants. Mean and standard deviation was calculated for continuous variables like age, parity. Percentage and frequencies were calculated for categorical variables like success versus failure of placental spontaneous expulsion. Independent ' $t$ ' test was also used. Chi square test was used to compare effectiveness between both groups. $\mathrm{P} \leq 0.005$ was taken as significant.

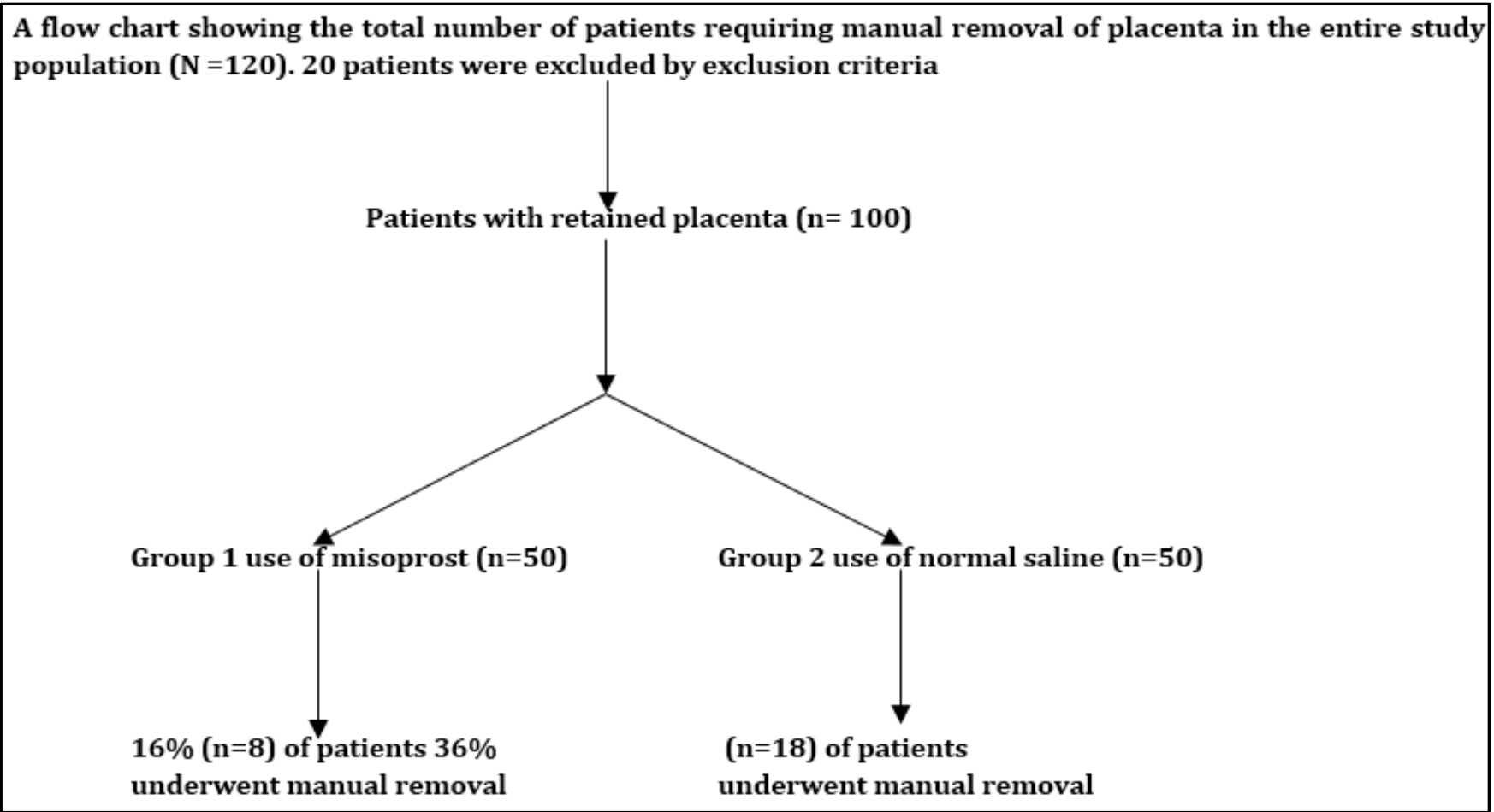

\section{RESULTS}

A total of 120 patients with retained placenta occurred at the stipulated study period. We have attended 100 retained placenta patients. Patients were equally divided into two groups. 50 patients in Group 1 received misoprostol and 50 patients of Group 2 received normal saline.

Maximum study population (62\%) was in the age group of 21 - 30 years and maximum study population (49\%) was primipara. Spontaneous onset of labour occurred in $66 \%$ of cases. Induction required in $10 \%$ and augmentation done in $24 \%$ cases.
As per our study manual removal was required in $26 \%$ of patients, while $74 \%$ had spontaneous removal.

Manual removal of placenta was more in Group 2 (Normal Saline) (69.2\%) than in Group 1 (Misoprostol) $(30.8 \%)$ and the difference was statistically significant $(\mathrm{p}<0.05)$. 


\begin{tabular}{|c|c|c|c|c|}
\hline $\begin{array}{c}\text { Baseline } \\
\text { Variables }\end{array}$ & Group & Mean (SD) & \begin{tabular}{|c|}
$t-$ \\
value
\end{tabular} & $\begin{array}{c}\text { p- } \\
\text { value }\end{array}$ \\
\hline \multirow{2}{*}{ Age (yrs.) } & 1 Misoprostol $(n=50)$ & $22.84(4.48)$ & \multirow{2}{*}{1.10} & \multirow{2}{*}{0.27} \\
\hline & 2 Normal saline $(n=50)$ & $22.04(2.43)$ & & \\
\hline \multirow{2}{*}{ Height (cm) } & 1 Misoprostol ( & 153.4 & \multirow{2}{*}{1.07} & \multirow{2}{*}{0.28} \\
\hline & 2 Normal & 153.40 & & \\
\hline \multirow{2}{*}{ Weight (kg) } & 1 Misoprostol $(\mathrm{n}=50)$ & 54.42 & \multirow{2}{*}{2.72} & \multirow{2}{*}{0.00} \\
\hline & 2 Normal saline $(n=50)$ & $51.72(4.80)$ & & \\
\hline \multirow{2}{*}{$\begin{array}{c}\text { Systolic BP } \\
\text { (mmHg) }\end{array}$} & 1 Misoprostol (n=50) & $117.40(6.44)$ & \multirow{2}{*}{4.02} & \multirow{2}{*}{0.00} \\
\hline & 2 Normal saline $(n=50)$ & 122.56 & & \\
\hline \multirow{2}{*}{$\begin{array}{c}\text { Diastolic BP } \\
(\mathrm{mmHg})\end{array}$} & 1 Misoprostol (n=50) & $74.56(4.33)$ & \multirow{2}{*}{2.38} & \multirow{2}{*}{0.01} \\
\hline & 2 Normal saline $(n=50)$ & $76.96(5.63)$ & & \\
\hline \multirow{2}{*}{$\begin{array}{l}\text { Gestational } \\
\text { age (wks) }\end{array}$} & 1 Misoprostol $(n=50)$ & 39.1 & \multirow{2}{*}{0.46} & \multirow{2}{*}{0.64} \\
\hline & 2 Normal saline $(n=50)$ & & & \\
\hline \multirow{3}{*}{$\begin{array}{c}\text { Duration of } \\
\text { third stage of } \\
\text { labour (time } \\
\text { calculated } \\
\text { after } 30 \\
\text { mins.) }\end{array}$} & & & \multirow{3}{*}{0.36} & \multirow[b]{3}{*}{0.00} \\
\hline & 1 Misopr & 20.6 & & \\
\hline & 2 Normal saline $(n=50)$ & $28.22(8.93)$ & & \\
\hline \multirow{2}{*}{$\begin{array}{l}\text { Amount of } \\
\text { blood loss } \\
(\mathrm{mL})\end{array}$} & $(n=50)$ & $292.00(1$ & \multirow{2}{*}{2.66} & \multirow{2}{*}{0.00} \\
\hline & 2 Norr & $408.20(245.10)$ & & \\
\hline \multirow{2}{*}{\begin{tabular}{|c|} 
Maternal \\
post-partum \\
Hb\% level \\
(gm)
\end{tabular}} & $1 \mathrm{Mis}$ & & \multirow[b]{2}{*}{1.01} & \multirow[b]{2}{*}{0.31} \\
\hline & 2 Normal saline $(n=50)$ & $9.40(0.85)$ & & \\
\hline \multirow{2}{*}{$\begin{array}{c}\text { Weight of } \\
\text { placenta }(\mathrm{gm})\end{array}$} & 1 Misoprostol $(\mathrm{n}=50)$ & $575.80(102.46)$ & \multirow{2}{*}{0.24} & \multirow{2}{*}{0.80} \\
\hline & 2 Normal saline $(n=50)$ & $570.70(114.55)$ & & \\
\hline \multicolumn{5}{|c|}{$\begin{array}{l}\text { Table 1. Distribution of Study Population according to } \\
\text { Baseline Variables and between Two Groups }(n=100)\end{array}$} \\
\hline
\end{tabular}

Independent ' $\mathrm{t}$ ' test shows significant association with systolic BP, weight of mother, diastolic BP, duration of third stage of labour (time calculated after 30 mins) and amount of blood loss ( $p$ value $<0.05$ ). The mean blood loss in our study was $292.00 \mathrm{~mL}$ in misoprostol group and $408.20 \mathrm{~mL}$ in saline group with significant $\mathrm{p}$ value $(<0.05)$. The mean duration of 3rd stage of labour was 24.45 mins with standard deviation of 9.8. Comparing between two groups 20.68 mins required in misoprostol group, while 28.22 mins in saline group with significant $p$ value $(<0.05)$.

\begin{tabular}{|c|c|c|c|c|c|}
\hline Variables & $\begin{array}{c}\text { Group 1 } \\
\text { (Misoprostol) }\end{array}$ & $\begin{array}{c}\text { Group 2 } \\
\text { (Normal } \\
\text { Saline) }\end{array}$ & $\begin{array}{c}\text { Chi- } \\
\text { Square }\end{array}$ & df & $\begin{array}{c}\text { P- } \\
\text { value }\end{array}$ \\
\hline $\begin{array}{c}\text { H/O } \\
\text { miscarriage }\end{array}$ & $8(16 \%)$ & $9(18 \%)$ & 1.01 & 1 & 0.60 \\
\hline H/O D and C & $4(8 \%)$ & $4(8 \%)$ & 0.00 & 1 & 1.00 \\
\hline $\begin{array}{c}\text { Spontaneous } \\
\text { labour }\end{array}$ & $33(66 \%)$ & $33(66 \%)$ & 0.00 & 1 & 1.00 \\
\hline $\begin{array}{c}\text { Blood } \\
\text { transfusion }\end{array}$ & $9(18 \%)$ & $18(36 \%)$ & 4.11 & 1 & 0.04 \\
\hline $\begin{array}{c}\text { Parity } \\
\text { (multipara) }\end{array}$ & $24(48 \%)$ & $27(54 \%)$ & 0.36 & 1 & 0.54 \\
\hline
\end{tabular}

Table 2. Distribution of Study Population according to Baseline Variables and between Two Groups $(n=100)$

\begin{tabular}{|c|c|c|c|c|c|c|}
\hline $\begin{array}{l}\text { Removal of } \\
\text { Placenta }\end{array}$ & $\mid \begin{array}{c}\text { Group 1 } \\
\text { (Misoprostol) }\end{array}$ & $\begin{array}{c}\text { Group } 2 \\
\text { (Normal } \\
\text { Saline) }\end{array}$ & Total & $\begin{array}{c}\text { Chi } \\
\text { Square }\end{array}$ & df & $\begin{array}{c}\text { P- } \\
\text { value }\end{array}$ \\
\hline Spontaneous & $\begin{array}{c}42 \\
(56.8 \%)\end{array}$ & $\begin{array}{c}32 \\
(43.2 \%)\end{array}$ & \begin{tabular}{|c|}
74 \\
$(100 \%)$ \\
\end{tabular} & \multirow{3}{*}{5.19} & \multirow{3}{*}{1} & \multirow{3}{*}{0.02} \\
\hline Manual & $\begin{array}{c}8 \\
(30.8 \%)\end{array}$ & $\begin{array}{c}18 \\
(69.2 \%)\end{array}$ & \begin{tabular}{|c|}
26 \\
$(100 \%)$ \\
\end{tabular} & & & \\
\hline Total & $\begin{array}{c}50 \\
(100 \%)\end{array}$ & $\begin{array}{c}50 \\
(100 \%)\end{array}$ & \begin{tabular}{|c|}
100 \\
$(100 \%)$
\end{tabular} & & & \\
\hline $\begin{array}{r}\text { Ible } \\
\text { Mc }\end{array}$ & tributior & Study Pc & oulation & te & & \\
\hline
\end{tabular}

\section{DISCUSSION}

This study was conducted in the Department of Gynaecology and Obstetrics, Bankura Sammilani Medical College and Hospital, Bankura from April 2015 to March 2016. In our study, maximum study population $(62 \%)$ was in the age group of 21 - 30 years. The mean age in the study (intraumbilical misoprostol) and control (saline) arms were 22.84 (4.48) and 22.04 (2.43) years respectively ( $p$ value $=$ 0.27 ). In a study done by Shaleen et al, the mean age of the participants did not differ significantly between the experimental and control groups $(24.52 \pm 5.16$ years vs. $25.83 \pm 4.66$ years, $p$ value $=0.374$ ). Our study included a more homogeneous population compared to that in Shaleen et al.

As per our study, manual removal was required in $26 \%$ of patients, while $74 \%$ had spontaneous removal. Manual removal of placenta was more in Group 2 (Normal Saline) (69.2\%) than in Group 1 (Misoprostol) (30.8\%) and the difference was statistically significant $(p<0.05)$. As per Cochrane review conducted by Carroli G, Bergel E ${ }^{4}$ compared with expectant management, umbilical vein injection of saline solution alone did not show any significant difference in the incidence of manual removal of the placenta.

The mean blood loss in our study was $292.00 \mathrm{~mL}$ (187.84) in misoprostol group and $408.20 \mathrm{~mL}$ (245.10) in saline group with significant $p$ value $(p=0.00)$. The mean blood loss was $350.10 \mathrm{~mL}$ with standard deviation of 224.965. The median of vaginal blood loss as per Shaleen et al was $30-75 \mathrm{~mL}$ in misoprostol group and $100-150 \mathrm{~mL}$ in saline group.

In our study, the mean duration of $3^{\text {rd }}$ stage of labour was 24.45 mins with standard deviation of 9.8. Compared between two groups 20.68 mins (9.27) was required in misoprostol group, while 28.22 mins (8.93) in saline group (with a $\mathrm{p}$ value of 0.00 ). As per Bider et $\mathrm{al}^{5}$ who studied the length of injection to placental delivery interval which was found to be 7.00 mins (3.20) in treatment group, while 13.00 mins (3.30) in saline group.

Regarding the secondary outcome as per our study blood transfusion was required only in 8 patients, while 18 in normal saline group with $\mathrm{p}$ value of 0.04 . As per Carroli et al, ${ }^{4}$ blood transfusion required in intraumbilical oxytocin group was greater than intraumbilical saline group and $p$ value of 0.68 which was not statistically significant.

Most common complication was fever. It occurred (10\%) in Group 1 and (8\%) in Group 2. The most commonly reported adverse effect of taking a misoprostol orally is diarrhoea. In clinical trials an average $13 \%$ of patients 
reported diarrhoea, which was dose related and usually developed early in the course of therapy (after 13 days) and was usually self-limiting (often resolving within 8 days), but sometimes (in $2 \%$ of patients) required discontinuation of misoprostol.

\section{Abbreviations}

ND- Normal Delivery, VD- Vaginal Delivery, GA- Gestational Age, LSCS- Lower Segment Caesarean Section, PPH- PostPartum Haemorrhage, PIH- Pregnancy-Induced Hypertension, MROP- Manual Removal of Placenta, WHOWorld Health Organisation.

\section{Limitation}

We have not estimated the sample size, but taken on convenience.

\section{CONCLUSION}

Retained placenta is a potentially life-threatening complication of 3rd stage of labour and associated with significant PPH. It is defined as failure of expulsion of placenta even after 30 mins of delivery of foetus. Only treatment option available till date is manual removal of placenta which requires a proper setup, surgeon and anaesthetists. These may not be available in poor resource settings and also MROP is associated with various risks. Intraumbilical misoprostol is a promising tool for treatment of retained placenta. It acts by placing misoprostol directly to the placental bed.

As per our study, we concluded that intraumbilical misoprostol significantly reduces the need for manual removal of placenta. Our study also concluded that the amount of blood loss was lower in misoprostol group. The total amount of blood loss during placental expulsion was significantly lower in the intraumbilical misoprostol arm. Intraumbilical misoprostol also decreases the median duration of placental expulsion in cases of retained placenta and thereby decreases the duration of 3rd stage of labour significantly.

As per our study duration of hospital stay, drop in haemoglobin and post infusion complication were not statistically significant in both the arms. Only fewer patients had post infusion complications. Thus, in our study intraumbilical misoprostol appeared as an efficacious and safer tool for treatment of retained placenta. It decreases the incidence of manual removal of placenta and blood loss associated with it. It also decreases the mean duration of 3rd stage of labour by causing early separation of placenta.

\section{REFERENCES}

[1] Gordon JE, Gideon H, Wyon JB. Midwifery practices in rural Punjab, India. Am J Obstet Gynecol 1965;93:734-7.

[2] Combs CA, Laros RK. Prolonged third stage of labour: morbidity and risk factors. Obstet Gynecol 1991;77(6):863-7.

[3] Tandberg A, Albrechtsen S, Iverson OE. Manual removal of placenta. Incidence and clinical significance. Acta Obstet Gynecol Scand 1999;78(1):33-6.

[4] Carroli G, Belizan JM, Grant A, et al. Intra-umbilical vein injection and retained placenta: evidence from a collaborative large randomised controlled trial. Grupo argentino de estudio de placenta retenida. Br J Obstet Gynaecol 1998;105(2):179-85.

[5] Bider D, Dulitzky M, Goldenberg M, et al. Intraumbilical vein injection of prostaglandin $\mathrm{F} 2$ alpha in retained placenta. Eur J Obstet Gynecol Reprod Biol 1996;64(1):59-61. 